\title{
DIVERSIFICATION OF THE CONTENT OF EDUCATION IN THE VOCATIONAL TRAINING OF FUTURE SPECIALISTS
}

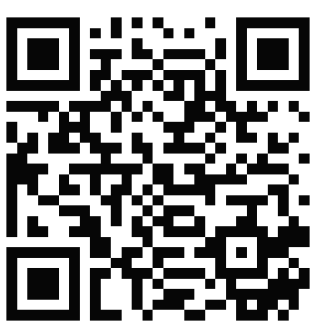

To cite this article:

\author{
Natalia Machynska, Dr. Sc., Assoc. Prof. \\ Head, Primary and Pre-School Education Department \\ Ivan Franko National University of Lviv, \\ Lviv, Ukraine \\ natalya_im@ukr.net \\ https://orcid.org/0000-0003-0309-7074
}

\section{Oksana Bilyk, PhD, Assoc. Prof.}

Assistant Professor, Foreign Languages Department,

Lviv Polytechnic National University

Lviv, Ukraine

lubik.anelia@gmail.com

https://orcid.org/0000-0002-8159-8088

Machynska, N. \& Bilyk, O. (2020). Diversification of the content of education in the vocational training of future specialists. Education: Modern Discourses, 3, 105-112.

https://doi.org/10.37472/2617-3107-2020-3-10

\begin{abstract}
"Educated citizens are the adornment of the nation" (inscription on the main building of the Ivan Franko National University of Lviv)
\end{abstract}

\begin{abstract}
The article is devoted to certain aspects of diversification of the content of professional training of future specialists in the therms of university education. It is noted that the concept of "diversification" has found its application in interdisciplinary areas - linguistics, politics, education; It is shown that in education sphere the term "diversification" covers diversity, diverse development, expansion of educational services, mastery of new activities not previously inherent in this industry. The authors proved that the construction of a new educational system of vocational training is possible provided that the principles of diversification are integrated into the educational process, in particular: humanization of education as a process and result of individual inculturation; democratization of education as an opportunity to realize a free, creatively active personality; creative nature of education as a necessary condition of spiritual and moral and socially significant personality; availability of the educational system; continuity of education. It is emphasized that the main elements of the diversification system of higher education in the socio-cultural sphere are the goals and content of education, methods, technologies, organizational forms, content and structural links of educational levels and their interaction.
\end{abstract}

Key words: content of education; diversification; higher education; personal-competence approach; professional training.

\section{INTRODUCTION. PROBLEM STATEMENT}

In the last twenty years, higher education in many countries has undergone significant changes, but the next decades will transform it even more. The expected changes will take 
place and are already taking place at all levels: at the level of lecture rooms of higher education institutions, at the state and world level. The current conditions of the pandemic have once again emphasized the need to update both the content of vocational training of specialists and the search for up-to-date forms and methods of its introduction.

The educational process in higher education institutions (HEI) presupposes that interaction between teachers and students should be based on a new educational paradigm, which, in turn, presupposes a shift of the emphasis from the content of education to new methods of pedagogical work, in which new technologies and analytical activities will play an important role. The impact of technologies on the educational process is becoming increasingly active and constantly increases, which is caused by the need to establish an active pedagogical education in the context of distance learning. Even in the conditions of a large number of students, education should be tailored to the individual needs and preferences of students. They will be largely involved in practice-oriented and interactive learning and will be aimed at self-development and learning not only in case of teachers but also in case of fellow students.

The new challenges which the society is facing are accompanied by the emergence of complex pedagogical issues. They may be solved by uniting the efforts of all pedagogical schools only on the basis of the potential of all educational systems, which, at the same time, are being diversified. Like many other public institutions, education is becoming more open to international cooperation. While previously the process of internationalization in education followed its development in the economy, today the need for diversification and advanced development in education is becoming more and more obvious. Such a statement is based on the enormous potential created by scientific and technological progress, on the growing role of science in the society of the future, on the inevitability of the formation and development of fundamentally new and global mechanisms of the life of human society. Under the influence of large-scale political and economic changes which are taking place in the society, the evolution of integrated systems of many countries, as well as in the conditions of the inevitability of global challenges to humanity, modern education is becoming increasingly global.

In modern conditions, world education is characterized by the principle of diversification, which determines the development of new qualities and functions, which were not previously inherent in the system.

\section{LITERATURE REVIEW}

We have probably heard the saying "Do not put all the eggs in one basket" more than once. This refers to diversification. Diversification is the process of reducing risks by distributing capital among different investment projects. In other words, investors money is distributed among different assets or among different asset classes for the purpose of receiving the maximum return for a certain level of risk. If you diversify your portfolio correctly, securities will not correlate or "move together".

The term "diversification" harks back to economics, which once again emphasizes how closely pedagogical education is connected to different sectors of the society. Education and culture, which have been accepted by people as a way of orientation in the process of life with the help of symbols, values, norms, rules, customs, etc., are the basis of socioeconomic and spiritual development of modern domestic society.

\section{METHODOLOGY}

Education decentralization can be measured on the basis of the location of decisionmaking affecting each of the four types of decisions in education systems: organization of instruction (curricula, textbooks, teaching methods, schedule); personnel management (hiring/firing, pay, assigning teaching responsibilities, and training); planning and structures; 
and resources and spending. This data represents a starting point for a more comprehensive measure of education decentralization in cross-country studies.

\section{MAIN RESULTS}

The level of development of the sociocultural sphere as the most important component of the quality of human life is one of the priority indicators of socioeconomic and sociopolitical growth of the society. The development of culture, education, and other social spheres contributes not only to the transition of a person to a higher level of development, but also acquires the features of one of the fundamental principles of the formation of humanistic personality.

The right to education is one of the fundamental human rights. The Declaration of Human Rights, proclaimed by the United Nations General Assembly on 10 December 1948, interprets the right to education as follows (Article 26):

1. Everyone has the right to education. Education shall be free, at least in the elementary and fundamental stages. Elementary education shall be compulsory. Technical and professional education shall be made generally available and higher education shall be equally accessible to all on the basis of merit.

2. Education shall be directed to the full development of the human personality and to the strengthening of respect for human rights and fundamental freedoms. It shall promote understanding, tolerance and friendship among all nations, racial or religious groups, and shall further the activities of the United Nations for the maintenance of peace.

3. Parents have a prior right to choose the kind of education that shall be given to their children.

In the modern conditions of modernization and humanization of the society, its transition to a new socially significant level, there is a crisis of the value system of an individual: past experience is devalued, it becomes increasingly difficult to perceive and explain the world from the standpoint of existing cultural norms and to perceive educational and sociocultural canons in their unity. In connection with this, there is a need to create a qualitatively new system of sociocultural education of an individual and to identify peculiarities of diversification of the content of education in the conditions of vocational training of future specialists.

Creation of a system of vocational higher education in the sociocultural sphere, as an area of the formation, development, and improvement of personality, ensures creation of objective conditions for an individual to expand knowledge, enrich experience, master ways of carrying out cognitive, practical, and sociocultural activities, which allows them to fulfill their creative potential.

The concept of "diversification" is currently used more and more actively. From NeoLatin this term literally means "change", "diversity", "to do" (Lomakina, 2006: p. 83).

Semantic analysis of approaches to the concept of "diversification" shows that this concept has been used in interdisciplinary areas and, accordingly, received a specific interpretation. Thus, the concept of "diversification" in linguistics is used to characterize the diversity of lexical composition of language as an indicator of speech culture; in politics it is interpreted as the "state policy aimed at creating a modern structure of the national complex: integrated multisectoral development".

In education, the term "diversification" covers diversity, diverse development, expansion of the types of educational services, mastery of new activities that were not previously inherent in this industry. Due to diversification, it became possible to focus higher education on "supporting significant differences in the programs and functions of higher education institutions in accordance with various sociocultural and socioeconomic needs of the society" (Zhernokleiev, 2014: p. 282). 
Analysis of approaches to identification of the concept of "diversification", its objects, purpose, content, and end result allows us to consider diversification in education in two forms: horizontal (expansion of educational services in the sociocultural sphere) and vertical (development of different types of sociocultural institutions of extended education).

By the way, such a classification of diversification is typical of economics, where horizontal diversification is the diversification of the portfolio by buying securities of one class. For example, a portfolio consists only of stock (or only of bonds) of different companies.

In the context of horizontal diversification, researchers distinguish between the following three trends in the formation of the educational system:

- creation of new state educational institutions;

- structural diversification of state educational institutions;

- creation of private, commercial, and non-commercial educational institutions of various types.

Vertical diversification presupposes expansion of the range and quality of educational services, as well as the use of new educational technologies (Kraevskii \& Polonskii, 2001).

The term "diversification in education" acquires independent meaning in V. Baidenko's studies, who has noted that diversification of education should be understood as a globalized process, within the framework of which there should be a departure from the traditional types of educational systems and from the principle of unitarity and unification of their structure (including the content of various types of educational programs, which are implemented by educational institutions and education authorities), and which should be considered as a philosophical category, one of the areas (trends) of the education reform, the principle of modern educational policy, the immanent characteristics of modern educational systems and academic culture (Baidenko, 1995).

F. Altbach speaks about the diversification of education as “.... the creation of new types of educational institutions to meet new needs ... this has been the most important trend of recent years, which will determine the formation of the academic system" (Altbach, 1992).

A. Smirnov believes that in the course of diversification a more flexible education system may be created, which will be capable of responding to any actions in the labor market, and considers it as a factor which simplifies access to prestigious university education and a way of improving the education system (Smirnov, 2012).

Some researchers consider diversification through the analysis of terms, content, and methods of teaching as an alternative to traditional education in the context of improving the educational process, which not only creates for an individual objective conditions for expanding basic knowledge, enriching experience, mastering ways of carrying out cognitive, practical, and social activities, but also contributes to spiritual, moral, creative, active, and socially significant formation thereof (Zhernokleiev, 2014; Baidenko, 1995).

In this regard, diversification of the content of education and training of future professionals can be defined as a general pedagogical principle of the development of the higher education system in the sociocultural sphere, the implementation of which will create conditions for the introduction of a variety of educational technologies, which should provide different versions of educational programs, taking into account individual abilities, skills, and needs of individuals, which will be a necessary condition for the formation of a new type of specialist.

In modern conditions, studies which presuppose identification of the impact of higher education in the professional sphere on the formation, purposeful development, and improvement of personality throughout the entire life are becoming increasingly relevant.

Diversification should contribute to the formation of a new system of higher professional education, which will contribute to the creation of innovative educational space. Formation of 
a new system is possible in the event of integration of the principles of diversification into the educational process, namely:

- humanization of education as a process and the result of the inculturation of individuals;

- democratization of education as an opportunity to form a free, creative, and active personality;

- the creative nature of education as a necessary condition for the formation of a spiritual, moral, and socially significant personality;

- accessibility of the educational system;

- continuity of education.

Based on factor operationalization, in terms of qualitative and quantitative composition, factors of diversification of the content of education in vocational training of future specialists can be divided into macro- and micro-factors.

Macro-factors include: the scale of socioeconomic and sociodemographic changes in the society; acceleration of the pace of development of sociocultural society; a purposeful policy on the organization of education in the sociocultural sphere; expansion of educational opportunities in the sociocultural sphere; scientific achievements in the social and humanitarian field; growing competition in the market of sociocultural services; mechanisms of state financing of education in the sociocultural sphere, attraction of extra-budgetary funds.

Micro-factors include: sociocultural competence at different educational levels; the need for the formation of a qualitatively new level of thinking and innovative lifestyle; systemic stability and reliability of sociocultural institutions capable of self-development; modernization of the content and technological support of sociocultural activities.

Based on the identified factors, it is worth noting that this process involves the implementation of changes in the structure and content of the system of vocational education; independence in the selection of educational programs in accordance with the demands of the society; development and introduction of appropriate innovative technologies of sociocultural activities, which cover the main value-oriented areas of the life of an individual. All this allows one to create favorable conditions for the formation of a spiritual, moral, creative, active, and socially significant personality.

Diversification of the system of higher education in the vocational training of future specialists is one of the social and educational phenomena that characterize the modern period of the development of the society, which is associated with the search for ways out of the crisis, along with the formation of a new educational paradigm focused on the humanization of an individual rather than on production; along with the increase of the degree of flexibility of the system of continuing education in the sociocultural sphere, its ability to quickly restructure, taking into account the increased requirements of the society for the results of sociocultural activities.

Formation of a diversification system of higher pedagogical education is carried out on the basis of primary provisions. In particular, these provisions include general ones, which can belong to any other educational system. According to A. Novikov, the ideas of educational development involve humanization, democratization (the grounds for classification - entities on which the objectives of professional education are focused); personality (humanization), society (democratization), as well as differentiation and flexibility (the grounds for classification - the content of education) and the unity of all the elements of the system (Novikov).

The main elements of the diversification system of higher education in the sociocultural sphere include objectives and content of education, methods, technologies, organizational forms, content and structural links of educational levels and their interaction, which are implemented through sociocultural activities.

We conducted the study of the problem of diversification of the content of higher 
education in the sociocultural sphere on the basis of a systemic and resource approaches, as well as on the approach based on personality and competence.

A systemic approach to the study of any process involves identification and analysis of the relationships, connections, and interactions of these elements at different educational levels and allows one to consider these elements taking into account their interconnection, to identify patterns of functioning and development of both the elements of the system and the system as a whole at certain stages of the formation of humanistic personality.

The resource approach involves comprehensive assessment of sociocultural activities, achievements of socially significant qualities of individuals, groups of individuals, and the society as a whole. Diversification is based on regulatory, administrative, institutional, environmental, financial, human, and information resources. Integrative use of resources leads to optimization of the educational function of sociocultural activities.

The approach based on personality and competence determines the formation of individual and professional competencies that ensure formation and development of the personality of every specialist in a higher education institution, as well as the formation of readiness for professional growth throughout life.

Thus, we consider diversification of the higher education system in the sociocultural sphere as an expansion of the summative hierarchical system of education, which is associated with the formation of a new paradigm of educational function of social activity, which gives a professional who is able to adequately respond to the spiritual and cultural needs of the society a competitive advantage.

The process of diversification of the higher education system can have a positive dynamics if:

- the content and technological component of the diversification of social and educational services provides targeted and meaningful continuity of all stages of learning;

- the diversification process is organized in accordance with the educational function of sociocultural activities;

- scientific, educational, and methodological support of the modern educational environment is carried out on the basis of the use of organizational forms, methods, tools and technologies of sociocultural activities;

- a unified system for monitoring the quality of social and educational services has been formed;

- the focus on the personality and activities in the educational process in the sociocultural sphere, as well as its depth and intensity, have been provided;

- all the resource potential of the university has been involved, and various services (research, scientific, methodological, diagnostic, monitoring, adaptation, etc.) that support the formation and development of personality are functioning.

Theoretical analysis of research on the problem of diversification of the content of education in the vocational training of future specialists and practical experience give us the opportunity to create certain conditions for the diversification of the content of educational programs, which ensure implementation of educational content in higher education institutions. Let's analyze them.

1. Fundamentalization of education, which presupposes in-depth theoretical, general educational, scientific, and vocational training of students and expansion of specialization in their vocational training.

2. Continuity and integration, which will allow one to master previously studied educational material and freely build an educational chain, choose individual educational programs that will take into account the skills and abilities of every student on the basis of basic knowledge and skills.

3. Completeness, which ensures that students will master educational program of the 
appropriate level and content. Completeness of education presupposes that students will undergo comprehensive training for future professional activities, which includes availability of the full range of knowledge, skills, and abilities necessary for successful performance of professional functions. Such holistic training presupposes not only readiness to perform professional functions, but also a certain level of intellectual development.

4. Accessibility allows one to choose an educational program in accordance with individual skills and abilities.

5. Openness and mobility provide an opportunity for individuals to improve their educational and professional level, by allowing one to choose their own individual trajectory in the educational space.

6. Levels, degrees, variety of functions and directions, which allow both an individual and an educational institution to form their own educational system. This condition will make the content of professional higher education more diverse, which will expand the capabilities of an educational institution, will make it more independent and autonomous in the conditions of emergence and development of competition in the world of educational services.

One of the paradoxes of the modern world is the growth of education in general and professional education in particular, which is extremely necessary for the society to function normally, as well as for economic, social, cultural, spiritual development and political prosperity, while the society does not allocate the resources that will allow education to properly perform its tasks when serving this particular society. If this contradiction is not solved, its disastrous consequences will be reflected in various areas and aspects of the life of the society.

Today, material and intellectual investments in education should be considered important, because it is on them that the level of education of modern youth will depend, which will determine the social reality in $10-15$ years.

For almost a millennium, HEIs have been public scientific centers, and they have been popularizing advanced knowledge. Over time, other functions were added to this basic function: more or less important, more or less topical ones. In different periods, educational institutions helped the church to spread Christianity, trained officials, strengthened national identity, became the engine of progress, led technological progress, etc. But we still perceive HEIs primarily as structures engaged in education and science.

At the same time, the reputation of HEIs and teachers is assessed solely on the basis of the results of their scientific activity, which is only intensified by the spread of world university rankings, and teaching itself is becoming less significant, which also results in the shift of attention from leadership and professional competencies to practitioners.

However, teaching can no longer remain secondary to science. Firstly, the vast majority of HEIs around the world are not engaged in research at all. Their achievements can only include high quality of educational programs. Secondly, the share of students who study in the world's most prestigious research universities and, accordingly, receive better education and opportunities for intellectual development is extremely small. No matter how talented and highly educated teachers are, the vast majority of students in the world value those who are more likely to give them the possibility to successfully complete a master's degree with minimal effort, and the possibility of mastering disciplines and professions at a high level is disregarded.

Such dissatisfaction and fuss are the result of not only the lack of impressive scientific results, but also inability to see a significant impact of higher education on the improvement of the level and productivity of specialists. Someday teaching will be assessed just as carefully and scrupulously as scientific activity. The assessment will be based on student feedback, as well as on the expert analysis of video recordings of classes, seminars, and laboratory work. Those who have succeeded in teaching will also finally receive recognition and various awards. 


\section{CONCLUSIONS}

One of the main problems which the massive scale of higher education is causing is that many students have significant gaps in education; accordingly, it is necessary to find approaches to the training of heterogeneous groups. Educational institutions should develop curricula not only for the purpose of ensuring accessibility of higher education to the population, but also for the purpose of ensuring that every student has a chance to successfully complete a program and receive a diploma, i.e for the purpose of reducing the dropout rate. All of this must definitely be done, but without compromising the quality of education.

State education policy should be designed in such a way so as to increase accessibility of higher education to socially and economically disadvantaged groups of the population, create and maintain a reliable quality control system, promote multidisciplinary HEIs and develop new fair mechanisms for the distribution of funding. It is difficult to find one right solution, but every country must try to find the right balance between the level of funding, accessibility and quality of higher education. In the long run, higher education system that is developing steadily is a guarantee of economic and social stability of any country (Knobel, 2015).

Thus, diversification of the content of vocational education in the socio-cultural sphere means expansion of the summative hierarchical system of continuing education, which is associated with the formation of a new paradigm of educational function of social and cultural activity, which gives a professional who is able to adequately respond to the spiritual and cultural needs of the society a competitive advantage.

\section{REFERENCES}

Altbakh, F. D. (1992). Modeli razvitiia vysshego obrazovaniia v predverii 2000 goda [Models of higher education development on the threshold of 2000]. Prospects: Issues Related to Education, 3, 40-58. (in Russian)

Baidenko, V. I. (1995). Diversifikatsiia srednego professionalnogo obrazovaniia:sushchnost usloviia puti realizatsii [Diversification of secondary vocational education: essence, conditions, ways of implementation]. Extended abstract of PhD's thesis. Moskva. (in Russian)

Knobel, Marcelo. (2015). Sustaining Quality and Massification: Is It Possible? International Higher Education, 80, 15

Kraevskii, V.V., Polonskii, V. M. (2001). Metodologiia dlia pedagoga: teoriia i praktika uchebnoe posobie [Methodology for teachers: theory and practice: study guide]. Moskva: Pedagogicheskaya assotsiatsiya Rossii. (in Russian)

Lomakina, T. Yu. (2006). Sovremennyi printsip razvitiia nepreryvnogo obrazovaniia [The modern principle of the development of continuing education]. Moskva: Nauka. (in Russian)

Novikov, A.M. (n.d.). Bazovoe professionalnoe obrazovanie: roblemi integratsii [Basic vocational education: Problems related to integration]. Retrieved 2020 from: http://www.anovikov. ru/artikle/kach_bpo.pdf (in Russian)

Smirnov, A.V. (2012). Teoreticheskie podkhody $\mathrm{k}$ obrazovatelnym klasteram $\mathrm{v}$ sisteme professionalnogo obrazovaniia [Theoretical approaches to educational clusters in the vocational education system]. Psychology, Sociology and Pedagogy, 12. Retrieved 2020 from: http://psychology.snauka.ru/2012/12/1456. (in Russian)

Zhernokleiev, I. (2014). Dyversyfikatsiia zmistu pidhotovky maibutnikh uchyteliv tekhnolohii $\mathrm{u}$ krainakh Pivnichnoi Yevropy [Diversification of the content of training of future technology teachers in the countries of Northern Europe]. Problemypidhotovky suchasnoho vchytelia,10 (Part 1), 280-285. (in Ukrainian) 